\title{
A INFLUÊNCIA DE ATRIBUTOS DE GESTÃO DA QUALIDADE ORGANIZACIONAL NA SATISFAÇÃO E NO COMPORTAMENTO DO DOADOR DE SANGUE
}

\author{
THE INFLUENCE OF ATTRIBUTES ORGANIZATIONAL QUALITY MAN- \\ AGEMENT IN SATISFACTION AND THE BEHAVIOUR AT BLOOD DONOR
}

\author{
Adriana Gonçalves Menezes ${ }^{1}$, Caissa Veloso e Sousa ${ }^{2}$, \\ Fernanda Fantini Pereira ${ }^{3}$ E Kelly Nogueira Guerra ${ }^{4}$
}

Recebido em: 30/05/2015 Aprovado em: 18/08/2015

\section{RESUMO}

A Administração Pública brasileira vem agregando ao seu modelo de gestão burocrático princípios e técnicas gerenciais, buscando ampliar e qualificar o atendimento às demandas sociais. A Fundação Hemominas, objeto deste estudo, é uma organização de saúde pública, que tem como finalidade estabelecer diretrizes para as políticas estaduais relativas à hematologia e hemoterapia, garantindo à população a oferta de sangue e hemocomponentes de qualidade. Tendo isso em vista, este artigo se propôs a investigar quais os aspectos do Sistema de Gestão da Qualidade, da Teoria do Comportamento do Consumidor e do Marketing Social podem contribuir para que uma organização pública que presta serviços hemoterápicos e hematológicos cumpra o que determina a Administração Pública Gerencial. Esta pesquisa foi feita com base na metodologia qualitativa e descritiva, por meio de estudo de caso, observação participante e pesquisa documental. O propósito do estudo foi alcançado, na medida em que se identificaram fatores que indicam o impacto potencial dos atributos da qualidade e dos princípios da Teoria do Comportamento do Consumidor e do Marketing Social na adesão à doação de sangue por doadores regulares e potenciais.

Palavras-chave: Administração pública; Gestão da qualidade; Comportamento do consumidor; Marketing social; Doador de sangue.

\begin{abstract}
The Brazilian Public Administration has been adding to its model of bureaucratic management principles and management techniques, seeking to expand and improve service to social demands. The Hemominas Foundation, object of this study, is a public health organization, which aims to establish guidelines for state policies related to hematology and haemotherapy, ensuring the population a supply of blood and products quality blood. This article aims to investigate which aspects of the Quality Management System, Consumer Behavior Theory and Social Marketing can contribute to a public organization that provides haemotherapic and hematologic services comply what determines the Public Administration Management. The study was based on qualitative and descriptive research methodology through case study, participant observation and document research. The purpose of the study was achieved, in that it were identified in the case studied factors that indicate the impact potential of the quality attributes and principles of the Consumer Behavior Theory and Social Marketing in adherence to blood donation by regular donors and potential.
\end{abstract}

Keywords: Public administration; Quality management; Consumer behavior; Social marketing; Blood donor.

${ }^{1}$ Mestre em Administração pela Faculdade Novos Horizontes, Brasil. E-mail: adriana.menezes@hemominas.mg.gov.br.

${ }^{2}$ Doutora em Administração de Empresas pela Universidade Federal de Minas Gerais (UFMG), Brasil. Professora e pesquisadora da Faculdade Novos Horizontes. E-mail: caissaveloso@yahoo.com.br.

${ }^{3}$ Especialista em Gestão da Qualidade pela Universidade Federal de Minas Gerais (UFMG), Brasil. E-mail: fernanda fantini@yahoo.com.br.

${ }^{4}$ Mestre em Administração Pública pela Fundação João Pinheiro (FJP), Brasil. E-mail: kelly.nogueira@hemominas.mg.gov.br. 


\section{Introdução}

A evolução socioeconômica, científica, tecnológica e cultural impõe às organizações brasileiras, tanto privadas quanto públicas, a conscientização acerca da importância da revisão dos seus modelos de gestão. De um lado, observa-se que as empresas privadas estão buscando alternativas inovadoras que possam contribuir para a sua sobrevivência e competitividade no mercado; de outro, nota-se que as organizações públicas estão procurando soluções para tornar mais eficiente o cumprimento de sua principal missão: prestar um serviço de melhor qualidade para a sociedade.

Nesse cenário, a administração pública brasileira vem agregando ao seu modelo de gestão burocrático princípios e técnicas utilizadas pelo estilo de administração de negócios, sem, contudo, perder a sua característica específica, que é administrar sem visar ao lucro, mas buscando a satisfação do interesse público.

A Administração Pública Gerencial é construída sobre o fundamento de que o Estado é uma grande empresa que tem a atribuição de oferecer serviços de qualidade ao cidadão, o qual, por sua vez, passa a ter a conotação de cliente e de consumidor na medida em que é considerado um contribuinte que, ao pagar seus impostos, tem o direito legal de receber em troca benefícios sociais, tais como: serviços públicos de saúde, educação e segurança. O modelo de Administração Pública Gerencial impõe aos seus gestores uma mudança de paradigma quando se considera que, além de cumprir as normas e seguir as leis peculiares ao modelo burocrático, deve-se saber gerenciar o desempenho de toda a cadeia dos processos organizacionais, mediante o estabelecimento de metas predefinidas e da aferição de indicadores, isto é, de medidas que permitem à organização avaliar até que ponto as atividades e ações que deveriam estar sendo desenvolvidas estão progredindo ou sendo concluídas rumo à meta estabele- cida (HERRERO FILHO, 2005). A aplicação e o emprego dos recursos públicos devem ser permanentemente monitorados e fiscalizados com base no princípio constitucional basilar da eficiência que impõe aos gestores consumirem menos recursos na produção de serviços públicos e serem eficazes de maneira a atender a real demanda da sociedade (BRASIL, 1988; SLOMSKI, 2005).

Em face do exposto, este artigo se propõe a investigar em que aspectos os conceitos, os princípios e as técnicas do Sistema de Gestão da Qualidade, da Teoria do Comportamento do Consumidor e do Marketing Social podem, juntos, contribuir para uma organização pública que presta serviços hemoterápicos e hematológicos no cumprimento do que determina a Administração Pública Gerencial, especialmente no que se refere à qualidade no atendimento $\mathrm{e}$ à assistência ao doador de sangue, no papel ambivalente que este ocupa enquanto cidadão e usuário de serviços públicos.

A unidade de observação da pesquisa foi a Fundação Centro de Hematologia e Hemoterapia de Minas Gerais (Fundação Hemominas), que é uma organização de saúde pública com personalidade jurídica própria, de direito público, vinculada à Secretaria de Estado da Saúde de Minas Gerais (SES-MG). A Fundação Hemominas tem como finalidade assegurar a unidade de comando e direção às políticas estaduais relativas à hematologia e hemoterapia, garantindo à população a oferta de sangue e hemocomponentes de qualidade (FUNDAÇÃO HEMOMINAS, 2013).

A Hemorrede da Fundação Hemominas é composta de uma unidade de Administração Central, que administra e estabelece as diretrizes para sete Hemocentros Regionais, nove Hemonúcleos Regionais, oito unidades entre Postos de Coleta e Agências Transfusionais e três Postos Avançados de Coleta Externa (PACE). 


\section{Referencial teórico}

Este capítulo versa sobre a Administração Pública Gerencial, o Sistema de Gestão da Qualidade, a Teoria do Comportamento do Consumidor e o Marketing Social, enquanto eixos temáticos que sustentam o conceito de uma organização pública com perfil gerencial voltada para resultados.

\subsection{Administração Pública Gerencial}

Segundo Matias-Pereira (2010), a Administração Pública Gerencial é uma forma de gestão orientada para os interesses e direitos do cidadão-cliente, e não às necessidades da burocracia. Parte do princípio de que é preciso combater o nepotismo e a corrupção com a maior utilização de indicadores de desempenho e controle de resultados em detrimento dos procedimentos rígidos burocráticos.

De acordo com Pereira (2007), a Administração Pública Gerencial focaliza a descentralização do ponto de vista político, transferindo recursos e atribuições para os níveis políticos regionais e locais, e a descentralização administrativa, por meio da delegação de autoridade para o "gerente público", termo empregado neste artigo para identificar o gestor público que tem o papel de fazer a administração dos processos e recursos públicos com base em planejamento estratégico e no desempenho organizacional pautado em resultados e no atendimento qualitativo ao cidadão.

A Administração Pública Gerencial surgiu a partir da década de 1970 como uma resposta à grande crise do Estado e à globalização da economia, isto é, dois fenômenos que impõem mundialmente a redefinição das funções do Estado e da sua burocracia. Pereira (2007) explica que a crise fiscal e a crise do petróleo deixaram o Estado ineficiente para reduzir custos, administrar os imensos serviços que the cabiam e proteger o patrimônio público contra os interesses particulares e a corrupção.

A discussão em torno do modelo gerencial tornou-se complexa e ganhou novos rumos a partir da metade da década de 1980. Basicamente, duas transformações foram operadas no modelo de gerencialismo: uma ligada à dinâmica intraorganizacional, priorizando os conceitos da flexibilidade, planejamento estratégico e qualidade; e outra mais radical e mais importante, que é a adoção de serviços públicos voltados para atender os anseios dos cidadãos-clientes (ABRUCIO, 1997).

\subsection{Planejamento Estratégico}

$\mathrm{Na}$ Administração Pública Estadual, o Planejamento Estratégico é elaborado seguindo as diretrizes orçamentárias e as políticas públicas de cada área de atuação. Em Minas Gerais, os instrumentos direcionadores do aspecto orçamentário são o Plano Plurianual de Gestão Governamental e o Plano Mineiro de Desenvolvimento Integrado do Estado de Minas Gerais. Quanto à política pública, no caso da hemoterapia que está inserida no setor da saúde, os instrumentos são o Plano Diretor de Regionalização, a Programação Pactuada Integrada e Plano Diretor de Sangue e Hemoderivados. Estes instrumentos orientam o planejamento segundo necessidades de infraestrutura e responsabilidades de cada gestor público na organização dos sistemas de saúde e no acompanhamento e na avaliação dos resultados que visam garantir e implementar a Política de Saúde em Minas Gerais, estabelecendo o referencial e as bases geográfica e populacional para o dimensionamento e a estimativa das demandas, para as necessidades dos serviços de saúde e para a alocação de recursos (FUNDAÇÃO HEMOMINAS, 2013a; MINAS GERAIS, 2014).

O Acordo de Resultados é mais um instrumento utilizado para pactuar os resultados que estabelece, por meio de indicadores e metas alinhadas às diretrizes do Plano Diretor, quais os 
compromissos serão assumidos pelas instituições públicas para melhorar sua eficiência e eficácia. Prevendo o efetivo comprometimento dos servidores do Estado, as metas pactuadas e os indicadores de desempenho permitem o acompanhamento dos processos e das rotinas (FUNDAÇÃO HEMOMINAS, 2013b).

Todas as diretrizes orçamentárias, as políticas públicas e os resultados pactuados com as instâncias superiores devem estar retratadas no planejamento estratégico de forma alinhada para permitir o cumprimento da missão e o alcance da visão de futuro da instituição.

\subsubsection{Balanced Scorecard (BSC)}

Para alinhar a organização com o seu Planejamento Estratégico e para traduzir as estratégias em objetivos, metas e iniciativas de fácil entendimento e compartilhamento entre os participantes da empresa, foi criado, por Kaplan e Norton, no início da década de 1990, o Balanced Scorecard (BSC) - um sistema de avaliação de desempenho empresarial que coloca a estratégia no centro do processo (DUTRA, 2008; HERRERO FILHO, 2005). $\mathrm{O}$ BSC - indicadores que impulsionam o desempenho - oferece aos executivos um referencial abrangente para traduzir os objetivos estratégicos da empresa em um conjunto coerente de indicadores de desempenho que incorpora medidas financeiras e não financeiras norteadas pela missão e pela estratégia da empresa (KAPLAN, NORTON, 2006a; HERRERO FILHO, 2005). No BSC, os objetivos e as medidas focalizam o desempenho organizacional sob quatro perspectivas, tal como demonstrado no Quadro 1.

\begin{tabular}{|c|l|}
\hline PERSPECTIVA & \multicolumn{1}{c|}{ BSC } \\
\hline Financeira & $\begin{array}{l}\text { Fornece um referencial de análise da estratégia de crescimento, } \\
\text { rentabilidade e risco. }\end{array}$ \\
\hline Cliente & $\begin{array}{l}\text { Mede o desempenho relacionado à estratégia de criação de valor } \\
\text { para o cliente e permite que os executivos identifiquem os seg- } \\
\text { mentos e mercados nos quais a organização competirá. }\end{array}$ \\
\hline Processos internos & $\begin{array}{l}\text { Mede o desempenho do tempo e a qualidade dos processos exis- } \\
\text { tentes, identificando os aspectos que podem ser melhorados. }\end{array}$ \\
\hline $\begin{array}{c}\text { Aprendizado e cres- } \\
\text { cimento }\end{array}$ & $\begin{array}{l}\text { Provêm de três fontes principais: pessoas, sistemas e procedimen- } \\
\text { tos organizacionais. Neste plano, os objetivos estratégicos são } \\
\text { alcançados via ações de reciclagem dos funcionários, aperfeiçoa- } \\
\text { mento da tecnologia da informação e dos sistemas e alinhamento } \\
\text { dos procedimentos e das rotinas organizacionais. }\end{array}$ \\
\hline
\end{tabular}

Quadro 1 - Perspectivas do BSC

Fonte: Kaplan e Norton (1997)

Para a organização converter suas iniciativas e seus recursos em resultados tangíveis de acordo com as perspectivas, utiliza-se uma representação gráfica denominada mapa estratégico, no qual os executivos comunicam aos empregados uma percepção clara de como suas funções estão ligadas aos objetivos gerais da organização, possibilitando que trabalhem de maneira coordenada e colaborativa em prol das metas almejadas pela empresa (KAPLAN; NORTON, 2006b).
Este sistema tem uma relação íntima com os sistemas de gestão da qualidade organizacional implantados, conforme discutido na seção seguinte.

2.3 Sistema de Gestão da Qualidade em Saúde

De acordo com Hargreaves (2001), para garantir a qualidade, as empresas prestadoras de serviços precisam atender às exigências e especi- 
ficações relativas à forma de produção dos produtos e serviços. A essa forma de produzir que atende a requisitos de garantia da qualidade chama-se de Sistema de Gestão da Qualidade.

A norma ISO 9000:2000 preceitua que o Sistema de Gestão da Qualidade estabelece a política e os objetivos da qualidade, bem como as diretrizes que vão possibilitar à empresa atingir tais objetivos. A norma prevê que é este sistema ajuda as organizações a aumentarem a satisfação do cliente, que é a razão de ser de qualquer empresa. Os requisitos de garantia do cliente podem ser especificados contratualmente ou determinados pela própria organização (HARGREAVES, 2001).

No mesmo sentido, Malik (1998) afirma que o Sistema de Gestão da Qualidade é constituído de ações de controle e garantia da qualidade com vistas aos desejos e hábitos dos consumidores, ao mesmo tempo em que se preocupa com o conhecimento dos custos. Couto (2009) ressalta que, no cenário atual brasileiro, marcado por uma economia globalizada e por um Estado cheio de dificuldades no atendimento às necessidades de saúde pública da população, as organizações não suportarão mais custos relacionados à má qualidade; à morbidade e mortalidade elevadas; ao retrabalho e desperdício de recursos; e ao pior dos custos que é o sofrimento do cidadão mal atendido nas organizações de saúde pública.

No Brasil, a implantação de sistemas de qualidade na saúde ocorreu a partir da década de 1990, quando foi firmado um convênio entre a Organização Pan-Americana de Saúde (OPAS) e a Federação Latino-Americana de Hospitais para a produção de um manual de padrões para Acreditação.

Conforme Scrivens (1995), a Acreditação é um sistema de avaliação para verificar o cumprimento de um conjunto de padrões de qualidade na assistência prestada, inspirado no princípio de que hospitais devem ser locais se- guros para a prática profissional e para o cuidado dos pacientes. Nessa acepção, a Acreditação tem origem na preocupação com as consequências advindas de eventuais falhas nos processos envolvidos na prestação de serviços: registro médico realizado em prontuário de paciente errado, troca de medicação, falhas de equipamentos, qualificação profissional inadequada etc. Esses eventos falhos podem ser prevenidos desde que os serviços de saúde avaliem seu desempenho e monitorem seus processos, o que nem sempre ocorre.

No setor de saúde brasileiro, entende-se que a gestão da qualidade é compulsória na medida em que a Resolução de Diretoria Colegiada (RDC) n. ${ }^{\circ}$ 63, de 25 de novembro de 2011, regulamento técnico da Agência Nacional de Vigilância Sanitária (ANVISA), dispõe sobre os requisitos de boas práticas de funcionamento para os serviços de saúde, fundamentados na qualificação, na humanização da atenção e gestão e na redução e no controle de riscos aos usuários e ao meio ambiente (ANVISA, 2013).

Entre 1999 e 2001, o Ministério da Saúde assinou um termo de compromisso e reconheceu a Organização Nacional de Acreditação (ONA) como instituição competente e autorizada a operacionalizar o desenvolvimento da Acreditação hospitalar no Brasil (COUTO, 2009). Em 2002, a ANVISA reconheceu a ONA como instituição competente e autorizada a operacionalizar o desenvolvimento do processo de Acreditação de Organizações e Serviços de Saúde no Brasil. Destarte, a ONA cria o Manual Brasileiro de Acreditação de Organizações Prestadoras de Serviços de Saúde (OPSS) para diversas áreas da saúde, tais como: hospitais, hemoterapia, nefrologia, terapia renal substitutiva, laboratório clínico, radiologia, diagnóstico por imagem, radioterapia e medicina nuclear e serviços ambulatoriais, terapêuticos ou pronto atendimento.

De acordo com o Manual da ONA (2010), os seus requisitos estão distribuídos dentro de três níveis que abordam 
três conceitos, os quais representam a base do Sistema Brasileiro de Acreditação e da sua metodologia: estrutura, processos e resultados. Em cada nível, busca-se expressar fundamentos reconhecidos internacionalmente e que podem se traduzir em melhores práticas e resultados em todos os processos da organização: visão sistêmica; liderança e estratégias; orientação por processos; foco no cliente; foco na prevenção; foco na segurança; responsabilidade socioambiental; cultura da inovação; melhoria contínua; e orientação para resultados. Os padrões são definidos em três níveis de complexidade que certificam a organização como Acreditada, Acreditada Plena ou Acreditada com Excelência.

Dentre os programas de Acreditação, destaca-se o Programa de Acreditação pela American Association of Blood Banks/Associação Brasileira de Hematologia, Hemoterapia e Terapia Celular (AABB/ABHH), que é fruto de uma parceria entre a Associação Brasileira de Hematologia, Hemoterapia e Terapia Celular e a Advancing Transfusion and Cellular Therapies Worldwide (AABB), anteriormente denominada American Association of Blood Banks (ABHH, 2013). Trata-se de um programa de normas de qualidade e padrões de segurança para o processo produtivo dos Serviços Técnicos de Hemoterapia e Bancos de Sangue, traduzido e adaptado à legislação brasileira, que foi concebido com o objetivo de manter e intensificar a qualidade e a segurança dos pacientes, dos doadores e das instalações nos processos de doação, transfusão e transplantes de tecido realizados no Brasil (ABHH, 2013; AABB, 2013). Os requisitos de qualidade e segurança do Programa de Acreditação pela $\mathrm{AABB} / \mathrm{ABHH}$ são implantados de acordo com o escopo de cada uma das seguintes unidades hemoterápicas: bancos de sangue, agências transfusionais, postos de coleta e áreas de apoio.

Consorciado a esses aspectos, a figura do consumidor, como ente que utili- za os serviços prestados pelos hemocentros, no papel tanto de doador de sangue quanto de receptor, deve ser destacada, conforme discutido nas seções a seguir.

\subsection{Teoria do Comportamento do Consu- midor}

A pesquisa acerca do comportamento do consumidor tem dois objetivos fundamentais: a previsão e o entendimento deste comportamento e o consequente descobrimento das relações de causa e efeito que possam influenciar ou educar o consumo (ENGEL; BLACKWELL; MINIARD, 2000). Na Teoria do Comportamento do Consumidor, faz-se necessário enfatizar o processo de troca, que envolve a transferência de algo tangível ou intangível, real ou simbólico, entre dois ou mais atores sociais, no qual o consumidor sempre reside em uma das extremidades dessa permuta. Ao analisar a troca, é importante examinar o que faz uma pessoa querer abrir mão de uma coisa para receber outra. Nesses casos, ambas as partes envolvidas lucram com a troca, porque cada uma recebe algo que valoriza mais do que aquilo de que abriu mão (MOWEN; MINOR, 2003).

Para que o processo de troca tenha êxito, é essencial que se entenda o comportamento dos consumidores, nas suas diversidades de gostos, desejos, estilos, crenças, culturas e valores, e que se identifiquem as forças que motivam e moldam o seu comportamento (ENGEL, BLACKWELL; MINIARD, 2000). Nesse aspecto, a motivação refere-se a um estado alterado de uma pessoa, o qual conduz a um comportamento voltado a um objetivo, sendo constituída de várias necessidades, sentimentos e desejos. A motivação começa com a presença de um estímulo que impulsiona o reconhecimento de uma necessidade. Este estímulo pode ser interno, quando parte do próprio consumidor que reconhece uma necessidade, ou externo, quando surge de uma mensagem 
de propaganda ou de um comentário de um amigo sobre um produto ou serviço (MOWEN; MINOR, 2003) ou, ainda, fruto de estratégias de marketing adotadas pelos órgãos públicos competentes, ora denominadas de Marketing Social.

\subsection{Marketing Social}

Enquanto a Teoria do Comportamento do Consumidor busca examinar o que influencia o comportamento e o processo decisório de consumo de um indivíduo, o Marketing Social visa impulsionar a mudança de comportamento desse indivíduo com o intuito de promover uma causa social.

Em meados da década de 1970, como forma de amenizar os efeitos negativos das crises mundiais, das guerras internas e externas, dos conflitos urbanos e de vários tipos de problemas sociais que ocorreram na época, desponta nos gestores públicos a preocupação com a adesão dos cidadãos a causas sociais diversas. O Estado precisou intervir na sociedade para cobrir as lacunas deixadas pelo mercado, o qual, por sua vez, já não conseguia mais se responsabilizar pela solução de tais problemas. Nesse contexto, surgiu a expressão Marketing Social, formulada por Philip Kotler em coautoria com Gerald Zaltman (VAZ, 2003; DONOVAN, HENLEY, 2010; WEINREICH, 2011).

Para Andreansen (1994), o Marketing Social foi originado a partir da necessidade de expandir o conceito de comportamento do consumidor para abranger algo não convencional, como, por exemplo, a promoção de doações de sangue. Uma característica importante do Marketing Social é que este, ao contrário do Marketing Convencional, não tem objetivos lucrativos (DONAVAN, 2010), devendo proporcionar relacionamentos benéficos para ambas as partes, como, por exemplo, governo e cidadão, e envolver a troca de valores, que em geral não são financeiros, como satisfação, ajuda e benefícios para a qualidade de vida (LEFBVRE, 2013), necessitando de engajamento de ambas as partes, emissor e receptor, para atingir os objetivos estipulados (KOHRAN, 2013).

O Marketing Social tem como objetivo, assim, reunir esforços para influenciar comportamentos humanos que promovam uma causa social que contribua para melhorar as áreas sociais de saúde pública, segurança, meio ambiente e desenvolvimento comunitário. A aplicação das técnicas desse tipo de marketing pode ser útil em vários programas sociais, tais como: redução da taxa de mortalidade infantil, cessação do uso do tabagismo, contenção da disseminação de Síndrome da Imunodeficiência Adquirida (AIDS) e diminuição do despejo de lixo nas ruas (VAZ, 2003; KOTLER, LEE, 2011; WEINREICH, 2011; LEFBVRE, 2013).

\section{Método}

Esta pesquisa foi feita com base na metodologia qualitativa e descritiva, por meio de estudo de caso, observação participante e pesquisa documental. Considerou-se como unidade de análise a Fundação Centro de Hematologia e Hemoterapia de Minas Gerais (Fundação Hemominas) e como unidade de observação o Sistema de Gestão da Qualidade utilizado na organização. Adotou-se o modelo de estudo de caso do tipo descritivo e ilustrativo, que, de acordo com Collis e Hussey (2005), permite, respectivamente, descrever a prática corrente e ilustrar práticas inovadoras adotadas pelas organizações. Utilizou-se a técnica de análise documental a partir da interpretação de documentos obtidos por meio de observação e disponibilizados no portal, na intranet e no sistema de gestão estratégica da Fundação Hemominas.

Visando fazer uma análise coerente com o propósito deste estudo, os resultados da observação e da pesquisa documental foram indexados de acordo com os eixos temáticos constantes nas seções deste 
artigo: Administração Pública Gerencial e Planejamento Estratégico - Balanced Scorecard (BSC); Sistema de Gestão da Qualidade; Teoria do Comportamento do Consumidor; e Marketing Social.

\section{Resultados}

\subsection{Administração Pública Gerencial}

Sobre a categoria classificada como Administração Pública Gerencial, identificou-se que a Fundação Centro de Hematologia e Hemoterapia de Minas Gerais (Fundação Hemominas) se orienta pelo Plano Plurianual de Ação Governamental, pela ação 4196 - Centro de Tecidos Biológicos e pelo programa 187 - Assistência Hematológica e Hemoterápica. Orienta-se, também, pelo Plano Mineiro de Desenvolvimento, conforme evidenciado nos objetivos 'Consolidar a rede de atenção à saúde em todo estado' e 'Estimular maior cuidado do com a própria saúde' (PLANO PLURIANUAL DE AÇÃO GOVERNAMENTAL, 2013).

As políticas de hemoterapia são estabelecidas pelo Plano Diretor Estadual de Sangue e Hemoderivados, ali- nhado com o Plano de Regionalização da Secretaria de Estado da Saúde e Política Nacional do Sangue. Quanto ao Acordo de Resultados, no qual são pactuadas metas com o governo estadual para a execução da Política de Sangue e Hemoderivados e concedidas autonomias que possibilitam a flexibilização das ações, a meta é otimizar o atendimento, beneficiando tanto o doador quanto o receptor de sangue, bem como os pacientes ambulatoriais (FUNDAÇÃO HEMOMINAS, 2013b; MINAS GERAIS, 2014).

As diretrizes, os objetivos, os indicadores e as metas pactuados no Acordo de Resultados estão alinhados com o Planejamento Estratégico Institucional da Fundação Hemominas, implantado desde 2005. O Planejamento segue os preceitos do BSC, considerando-o um sistema de gestão estratégica que é norteado pela missão e visão da organização (Figura 1) e como o ponto de partida do Planejamento Estratégico, que, ao ser compartilhado com toda a organização, possibilita um trabalho coordenado e colaborativo em prol dos objetivos e das metas organizacionais (KAPLAN; NORTON, 2006b).

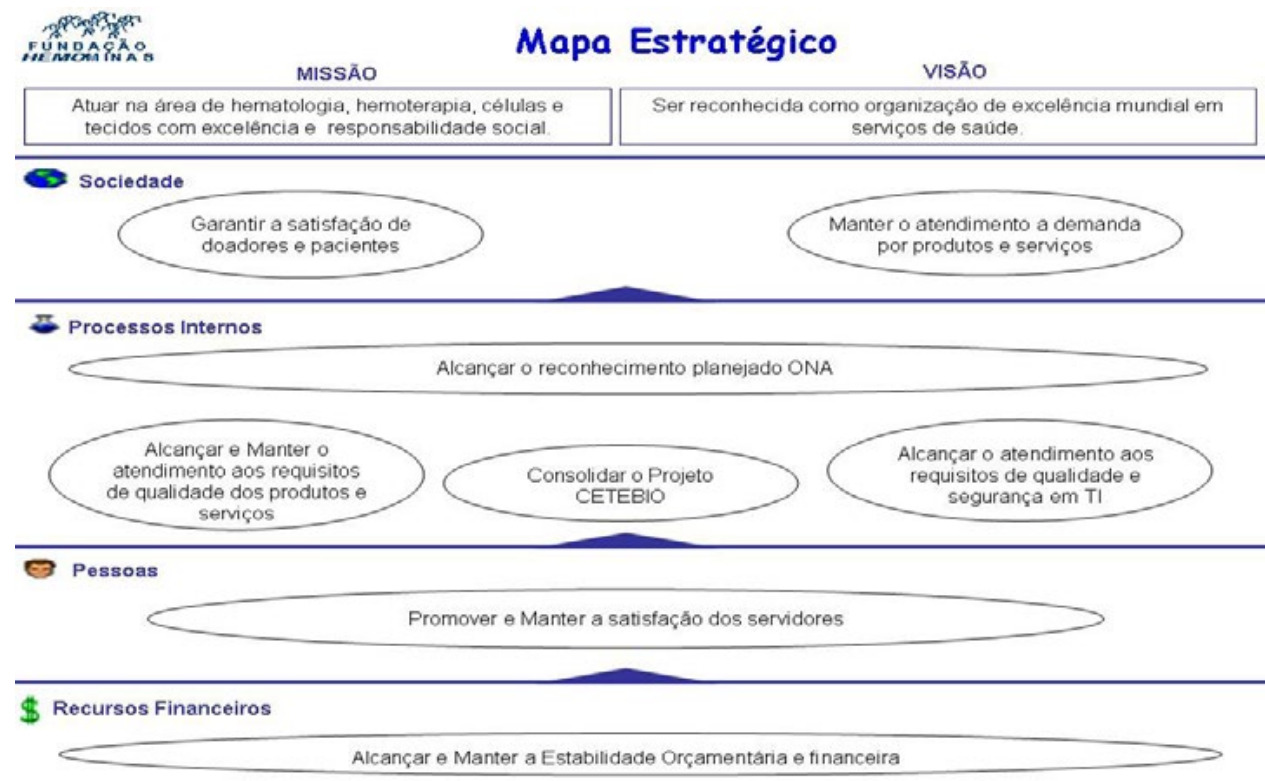

Figura 1 - Mapa Estratégico da Fundação Hemominas Fonte: Fundação Hemominas (2013c) 
O mapa estratégico está desdobrado em nível tático e operacional em toda a instituição por meio de ações e indicadores. A cada dois meses, a alta direção realiza a Análise Crítica dos resultados, avaliando o desempenho dos seus processos e convertendo suas iniciativas, seus recursos e suas ações em resultados, com base nas perspectivas da sociedade, dos processos internos, das pessoas e dos recursos financeiros, tal como preceituado por Kaplan e Norton (2006b). Para cada perspectiva e objetivo estratégico, todas as unidades da Fundação Hemominas estabelecem ações estratégicas, metas e indicadores de desempenho (FUNDAÇÃO HEMOMINAS, 2013c).

\subsection{Sistema de Gestão da Qualidade}

A Fundação Hemominas deu os primeiros passos para a implantação de um Programa de Qualidade em 1997. Inicialmente, adotou-se a tradicional ferramenta de qualidade conhecida como $5 \mathrm{~S}^{5}$. Nessa fase, foram incorporados outros instrumentos de qualidade, tais como o Procedimento Operacional Padrão (POP) e o Ciclo PDCA ${ }^{6}$ (CIOFF, PROIETTI, RODRIGUES, 2013; FUNDAÇÃO HEMOMINAS, 2013d, 2013e; RIBEIRO, 2006).

Posteriormente, a Fundação Hemominas aderiu ao Programa da Qualidade do Sangue (PQS), lançado em 1999 pelo Ministério da Saúde. De acordo com as diretrizes e os objetivos observados pelo PQS, a estratégia de orientação aos órgãos executores das atividades hemoterápicas que a ele aderiam fundamentava-se no binômio Avaliar e Agir, em que a fase de avaliação representava um esforço de autodiagnóstico organizacional e a fase de

${ }_{5}^{5} \mathrm{~S}$ : técnica de modelo japonês de gestão da qualidade que vem de cinco palavras japonesas que começam com a letra "S": Seiri - senso de utilização, seleção e descarte; Seiton - senso de organização e arrumação; Seiso - senso de limpeza; seiketsu - senso de saúde, higiene e padronização; e Shitsuke - senso de disciplina e autodisciplina.

${ }^{6}$ PDCA: instrumento de gestão da qualidade conhecido como Controle de Processos ou Ciclo de Deming, cujo princípio é tornar os processos mais claros e ágeis na execução da gestão. As iniciais em inglês representam os vocábulos: plan, do, check e act, que, traduzidos para português, significam: planejar, implementar, verificar e agir. ação representava a implantação de programas de melhoria (FUNDAÇÃO HEMOMINAS, 2013d; BRASIL, 2013).

Entre 2001 e 2002, foi criado e aprovado o Programa de Qualidade específico da Fundação Hemominas (PQFH), com a missão de desenvolver práticas de gestão pública de excelência, fazendo com todas as suas unidades se destacassem pela agilidade, pela credibilidade, pela criatividade, pela ética, pela racionalidade, pelo respeito, pela responsabilidade social e pela valorização do ser humano (CIOFF, PROIETTI, RODRIGUES, 2013; FUNDAÇÃO HEMOMINAS, 2013d, 2013e; RIBEIRO, 2006).

O Sistema de Gestão da Qualidade da Fundação Hemominas é conferido por meio da implementação dos projetos de Certificação da Qualidade de seus serviços por agências avaliadoras da Organização Nacional de Acreditação (ONA) e do Programa de Acreditação pela American Association of Blood Banks/Associação Brasileira de Hematologia, Hemoterapia e Terapia Celular (AABB/ABHH). A Fundação Hemominas foi contemplada pelo Ministério da Saúde para fazer parte do seu projeto de certificação pela $\mathrm{AABB}$ em cinco hemocentros brasileiros.

Tendo em vista a visão de futuro da Fundação Hemominas de ser reconhecida como organização de excelência mundial em serviços de saúde, a organização está qualificando-se para se certificar no nível mais alto da ONA, isto é, o nível de Acreditada com Excelência, bem como em todos os níveis do Programa de Acreditação pela AABB/ ABHH. Para tanto, a alta administração da Fundação Hemominas conta com todos os servidores, além de uma estrutura constituída de uma equipe técnica na administração central e em todas as demais unidades. Com essa estrutura, a organização analisa e adéqua suas rotinas e seus processos para atender aos requisitos de qualidade da ONA e da AABB (FUNDAÇÃO HEMOMINAS, 2013d). 
4.3 Teoria do Comportamento do Consumidor

No contexto da Teoria do Comportamento do Consumidor, atentou-se à correlação observada entre o processo de troca na concepção teórica de Mowen e Minor (2003) e o processo de troca entre a doação e distribuição do sangue doado. Nessa perspectiva, o processo de doação e transfusão de sangue envolve a transferência de produto, serviço e valor humano entre três atores envolvidos na troca: o doador, o receptor e a unidade prestadora de serviços públicos hemoterápicos, que, neste caso, é a Fundação Hemominas.

De um lado, o doador participa da troca com o seu sangue e com seu ato de solidariedade, e, de outro, o receptor do sangue participa da troca com o recebimento da transfusão do sangue para tratar da sua saúde e com seu sentimento de gratidão. Em uma terceira face, a Fundação Hemominas participa da troca, prestando um serviço público de atendimento e assistência hemoterápica, por meio de procedimentos hemoterápicos que vão possibilitar a um cidadão doar seu sangue e a outro receber o sangue doado.

Quanto ao benefício esperado por cada parte envolvida no processo de troca, entende-se que a Fundação Hemominas se beneficia pelo cumprimento de sua missão, o doador beneficia-se de acordo com o valor que ele considera para sua decisão e seu ato de doar e o receptor beneficia-se por ter recebido a assistência hemoterápica e pelo ato de solidariedade de um cidadão que forneceu o sangue. Para que esse processo de troca tenha êxito, é essencial entender o comportamento do doador enquanto consumidor que precisa concluir a doação com satisfação, tanto pela sua atitude solidária quanto pelo atendimento recebido pela Fundação Hemominas.

Engel, Blackwell e Miniard (2000) asseveram que o comportamento do consumidor depende de suas crenças, suas culturas e seus valores. Dentre as hipóteses que explicam as origens culturais da quantidade insuficiente de doadores no Brasil, destaca-se o fato de o país nunca ter passado por guerras e grandes catástrofes, e, por conseguinte, de o brasileiro não considerar o sangue como um remédio insubstituível que salva vidas. Outra hipótese levantada diz respeito ao entendimento de alguns brasileiros que associam sangue a laços de sangue familiares, não considerando, assim, que a doação é uma atitude altruísta, na qual se desconhece quem receberá seu sangue (GONTIJO, 2007).

Identificou-se que a meta institucional para a satisfação do doador, o cálculo do indicador que mede o percentual de satisfação dos doadores e a Pesquisa de Satisfação de Cliente Externo são instrumentos estratégicos da Fundação Hemominas que apresentam dados e informações que possibilitam o estudo do comportamento do doador.

Para alimentar o indicador estratégico que mede o percentual de satisfação dos doadores, a Fundação Hemominas realiza semestralmente a Pesquisa de Satisfação de Cliente Externo em todas as suas unidades. De acordo com o Procedimento de Gestão que normatiza a pesquisa, cada doador é direcionado e estimulado a responder a pesquisa em um questionário disponibilizado nos pontos de abordagem, localizados nas lanchonetes do setor de coleta e no setor de atendimento ao doador. Os formulários são preenchidos e depositados em urnas recolhedoras ou depositários de acordo com os pontos de aplicação do questionário (FUNDAÇÃO HEMOMINAS, 2013h).

Os Núcleos de Qualidade da Fundação Hemominas recolhem, sistematicamente, os registros de avaliação nas urnas e identificam as reclamações, as sugestões e os elogios. Os registros são tratados pelas diretorias e coordenações da seguinte forma: para cada reclamação, é avaliada a pertinência e o tipo de não conformidade cometida frente aos requisitos legais, normativos e de qualidade. Com base em metas prees- 
tabelecidas, os resultados das pesquisas são compilados, analisados, discutidos e registrados no Sistema de Gestão Estratégica da Organização. Para cada não conformidade, cria-se um plano de ação corretiva ou preventiva (FUNDAÇÃ̃O HEMOMINAS, 2013h).

\subsection{Marketing Social}

Para associar os resultados da pesquisa aos preceitos teóricos do Marketing Social, iniciou-se a análise com base na afirmação de Mowen e Minor (2003) sobre a necessidade de as organizações executarem ações de marketing para oferecer serviços com valor agregado, possibilitando, assim, a promoção e a oferta de serviços que vão representar o valor esperado pelo indivíduo, de maneira tal que se estabeleça o processo de troca e que o consumidor fique satisfeito e fidelizado.

Nesse sentido, ressalta-se o papel e as atividades desenvolvidas pela Gerência e Equipe de Captação de doadores da Fundação Hemominas, que têm a missão de captar candidatos à doação e de fidelizar doadores por meio de programas de educação e informação direcionada à população, na busca incessante da formação de uma consciência coletiva em relação à importância da realização da doação de sangue voluntária e habitual como ato de cidadania e responsabilidade social (GONTIJO, 2007).

Dentre as iniciativas para captação e aculturamento da doação de sangue altruísta e regular, destaca-se o Programa para Formação do Doador do Futuro, lançado em 1987, que tem o objetivo de preparar crianças e jovens para uma futura doação de sangue consciente e responsável. A Fundação Hemominas faz um trabalho educativo, que desmistifica os tabus e as crendices sobre o processo da doação de sangue, trazendo, como consequência, uma mudança comportamental que visa a reflexos positivos para a população (GONTIJO, 2007).
O Programa Doador do Futuro é realizado por meio de ações educativas junto às escolas, com apoio de palestras, peças teatrais e oficinas de trabalho em que os alunos fazem cartazes que transmitem mensagens de valorização da doação voluntária de sangue. Outra ação educativa de destaque é feita pelo "Hemotur" - uma atividade em que os alunos visitam a Fundação Hemominas e, guiados pelos profissionais da captação, conhecem os processos envolvidos na doação de sangue, percorrendo os setores e assistindo a palestras e a vídeos institucionais (GONTIJO, 2007).

No intuito de oficializar as ações desenvolvidas, a Fundação Hemominas firmou parcerias com a Secretaria $\mathrm{Mu}$ nicipal e Estadual de Educação, com o Centro de Apoio aos Profissionais de Ensino e com a Câmara de Vereadores de Belo Horizonte. No período de 2004 a 2011, o Programa Doador do Futuro contabilizou 5.208 palestras, alcançando 220.919 mil alunos das escolas de Minas Gerais. Já se colhe frutos do Programa Doador do Futuro, uma vez que, frequentemente, a Fundação Hemominas recebe grupos de alunos, que, ao completar a idade permitida para doação, realizam a primeira doação, tornando-se, então, doares de sangue regulares almejados (GONTIJO, 2007; FUNDAÇÃO HEMOMINAS, 2013f).

Outras atividades de captação de doadores são feitas por meio da Captação Hospitalar, em que a direção, os funcionários e os médicos dos hospitais comprometem-se a ter práticas sistemáticas de conscientização para doação, abordando os familiares de pacientes que necessitaram de reserva transfusional, isto é, de pacientes que possivelmente vão precisar de transfusão de sangue, ou os usuários dos serviços hospitalares em geral, a fim de mobilizá-los para a realização de doação de sangue de forma responsável e regular (GONTIJO, 2010).

A Fundação Hemominas faz coletas externas, que se constitui como uma atividade de captação e cadastro de can- 
didatos à doação e à coleta de sangue de pessoas que atendem aos critérios para doação. As coletas externas são realizadas em instituições, escolas, empresas, universidades e municípios que não possuem uma unidade hemoterápica, com o objetivo de promover a doação de sangue (FUNDAÇÃO HEMOMINAS, 2013g).

Junto às ações de captação de doadores, a Assessoria de Comunicação Social (ACS) da Fundação Hemominas dá suporte ao regular comparecimento de doadores e à manutenção de estoques de sangue, por meio dos programas e campanhas de publicidade que informam a sociedade sobre a importância e a necessidade da doação de sangue. Dentre as suas diversas frentes de trabalho, a ACS atua em forma de notícia pela televisão, pelo rádio ou pelos jornais e pelas revistas, organizando eventos locais, regionais, estaduais, nacionais e internacionais, com destaque para o Evento de Diplomação de Doadores Fidelizados em comemoração ao Dia Nacional do Doador Voluntário de Sangue, comemorado todo dia 25 de novembro. A ACS é autora do Jornal Hemominas, publicado trimestralmente com distribuição nacional e internacional e responsável pelo conteúdo noticioso do Portal Hemominas e do Portal Minas On-Line (SILVA, 2008).

Destaca-se, também, o Projeto Doe seu melhor tempo, elaborado e executado pela ACS, cujo objetivo é fazer parcerias institucionais entre empresas de comunicação e a Fundação Hemominas, para veiculação de peças publicitárias em rádio e televisão, com o intuito de apresentar conceitos de doação de sangue como uma atitude cidadã à sociedade para o desenvolvimento da cultura da doação consciente, que promova a ampliação do percentual populacional de doadores fidelizados e a manutenção da segurança da coleta de sangue e da transfusão realizadas (SILVA, 2011).

Associando o Marketing Social à realidade da Fundação Hemominas, de acordo com Kotler e Lee (2011), verifi- cou-se que os profissionais da captação e da comunicação social têm a tarefa desafiadora de influenciar continuamente o comportamento das pessoas a se tornarem doadoras de sangue regulares. Nesse sentido, torna-se necessário potencializar os esforços para captar, incentivar e vfidelizar os doadores regulares.

Condizente com Lebvre (2013) no que se refere aos valores trocados no Marketing Social, Gontijo (2010) afirma que o hábito de doar sangue é peculiar, tendo em vista que esse ato não oferece vantagem material e não traz prazer físico, sendo, portanto, um hábito adquirido por um estímulo moral forte ou um exemplo de pessoas que exercem forte influência sobre o indivíduo, tal como os pais e os professores.

Segundo Gontijo (2010), no Brasil, existe uma falta crônica de doadores de sangue que pode ser explicada por diversos motivos, tais como: o medo que a pessoa tem de adquirir uma doença pelo ato da doação, principalmente a Síndrome da Imunodeficiência Adquirida (AIDS); o medo da picada da agulha; e as crendices de que a doação aumenta o volume do sangue, engrossando-o ou afinando-o. Destarte, percebe-se que mais grave que os motivos citados, é a desinformação, uma vez que os receios comumente alegados são improcedentes ou passíveis de serem desmistificados.

Diante do exposto, considera-se que o panorama da doação identificado nesta pesquisa implica que as ações de Marketing Social na Fundação Hemominas, realizadas entre as áreas de captação e comunicação de forma conjunta, porém específicas, têm trabalhado permanentemente para influenciar as pessoas que estão equivocadas quanto aos aspectos da doação de sangue a rejeitarem comportamentos pautados em medos e tabus e a aceitarem novos comportamentos com base no entendimento de que o sangue do ser humano é um remédio insubstituível e que, portanto, é essencial para salvar vidas, sendo um ato voluntário e individual de responsabilidade social. 


\section{Considerações finais}

Este artigo se propôs a investigar a influência de atributos da Gestão da Qualidade, da Teoria do Comportamento do Consumidor e do Marketing Social para que uma organização pública que presta serviços hemoterápicos e hematológicos possa cumprir o que determina a Administração Pública Gerencial. Considera-se que o propósito do estudo foi alcançado na medida em que se verificou que os atributos da qualidade internalizados culturalmente pela Fundação Centro de Hematologia e Hemoterapia de Minas Gerais (Fundação Hemominas), representados neste artigo por meio da apresentação do modelo de administração pública gerencial, traduzido pelos instrumentos de planejamento e de gestão da qualidade utilizados pela organização, coadunam com as premissas da Teoria do Comportamento do Consumidor e do Marketing Social.

Este estudo de caso permitiu constatar que a Fundação Hemominas implementa ações e esforços para se qualificar a partir dos seus processos internos, de maneira a se estruturar adequadamente para atender ao cidadão, em seus direitos públicos e interesses sociais, enquanto doador de sangue e consumidor de um serviço público.

Os programas e projetos das equipes de qualidade, captação e comunicação da Fundação Hemominas e de sua hemorrede foram reconhecidos como atividades clássicas para o estudo do comportamento do doador de sangue, bem como para a promoção de mudanças de comportamento dos indivíduos nas suas decisões de se habituarem a doar sangue regularmente. O Sistema de Gestão da Qualidade está sendo implantado com êxito, apresenta resultados positivos e busca a melhoria contínua do processo de maturação da organização.

Contudo, considera-se oportuno dar continuidade a este estudo para superar as limitações típicas da metodo- logia utilizada, fazendo uma pesquisa sobre os resultados apresentados pelas Pesquisas de Satisfação do Doador face ao Sistema de Gestão da Qualidade a fim de proceder a uma análise mais efetiva sobre o impacto deste sistema no cenário da doação de sangue na Fundação Hemominas. Para estudos futuros, sugere-se, também, identificar outros fatores que dificultam a adesão à doação de sangue por doadores regulares, na perspectiva do estudo do comportamento do doador, bem como avaliar de maneira mais detalhada as campanhas de doação de sangue frente ao Marketing Social.

\section{Referências}

1. ABRUCIO, F. L. O impacto do modelo gerencial na administração pública. Um breve estudo sobre a experiência internacional recente. Cadernos ENAP. n. 10. Brasilia: Fundação Escola Nacional de Administração Pública, 1997.

\section{ADVANCING TRANSFUSION AND CELLULAR THERAPIES WORLDWIDE. AABB Name Chan- ge. Disponível em: <http://www.aabb. org/about/who/Pages/namechange. aspx>. Acesso em: 11 mai. 2015.}

3. AGÊNCIA NACIONAL DE VIGILÂNCIA SANITÁRIA. RDC n⿳ $\mathbf{6 3}$, de 25 de novembro de 2011. Disponível em:< http://www.anvisa.gov.br/hotsite/ segurancadopaciente/documentos/rdcs/ RDC\%20N\%C2\%BA\%2063-2011. pdf> Acesso em: 04 mai. 2015.

4. ASSOCIAÇÃO BRASILEIRA DE HEMATOLOGIA, HEMOTERAPIA E TERAPIA CELULAR. O que é o programa. Disponível em: <http:// www.abhh.org.br/pt-br/associacao/ acreditacao/o-que-e-o-programa>. Acesso em: 11 mai. 2015.

5. ASSOCIAÇÃO BRASILEIRA DE
HEMATOLOGIA, HEMOTERAPIA 
E TERAPIA CELULAR. Tipos de acreditação. Disponível em: $<\quad$ http://www.abhh.org.br/pt-br/ associacao/acreditacao/tipos-deacreditacao>Acesso em: 11 mai. 2015a.

6. ANDREASEN, A. R. Social Marketing: Its Definition a Domain. Journal of Public Policy and Marketing, v.13, n.1, p. 108-114.

7. BRASIL. Constituição (1988) Constituição da República Federativa do Brasil. Brasília, DF, Senado, 1988. Disponível em: <http://www. planalto.gov.br/ccivil 03/constituicao/ constitui\%C3\%A7ao.htm>. Acesso em: 10 mai. 2015.

8. BRASIL, MINISTÉRIO DA SAÚDE. Programa de Qualidade de Sangue: instrumento de auto-avaliação dos órgãos executores das atividades hemoterápicas. Brasilia: [s.n.], 1999. Disponível em: <http://bvsms.saude.gov.br/ bvs/publicacoes/programa_qualidade sangue.pdf $>$. Acesso em 22 mai. 2015.

9. CIOFF, J. G. M. PROIETTI, A. B. F. C. RODRIGUES, D. O. W. Hemominas: aplicação e impacto do instrumento de auto-avaliação de 250 pontos do Gespública. Rev. bras. hematol. hemoter. São Paulo, v. 30, n. 2, p. 101107, 2008.

10. COLlis, J.; HUSSEY, R. Pesquisa em Administração: um guia prático para alunos de graduação e pós-graduação. 2. ed. Porto Alegre: Bookman, 2005.

11. COUTO, R. C.; PEDROSA, T. M. G. Coleção Metodologia da Acreditação: técnicas básicas para a implantação da Acreditação. v. 1. Belo Horizonte: Iag-Saúde, 2009.

12. DONOVAN, R.; HENLEY, N. Principles and Practice of Social Marketing: an international perspective. New York: Cambridge University Press, 2010.

13. DUTRA, A. et al. Estratégias: formulação, implementação e avaliação: o desafio das organizações contemporâ- neas. São Paulo: Saraiva, 2008.

14. ENGEL, J. F.; BLACKWELL, R. D.; MINIARD, Paul W. Comportamento do Consumidor. 8 ed. Rio de Janeiro: LTC, 2000.

15. FUNDAÇÃO HEMOMINAS. Institucional. Disponível em: < http://www.hemominas.mg.gov. $\mathrm{br} / \mathrm{hemominas} / \mathrm{menu} / \mathrm{aInstituicao} /$ historico.html>. Acesso em: 16 abr. 2015.

16. Plano Diretor. Disponível em: <http://www.hemominas.mg. gov.br/intranet/institucional/diretrizes/ planoDiretor/ $>$. Acesso em: 17maio 2015a.

17. Acordo de

Resultados. Disponível em: < http://www.hemominas.mg.gov. br/intranet/institucional/diretrizes/ acordoResultados/>. Acesso em: 17 maio 2015 b.

18. Planejamento Estratégico. Disponível em: < http://www.hemominas.mg.gov.br/intranet/institucional/ diretrizes/planejamentoEstrategico/planejamentoEstrategicoInstitucional/>. Acesso em: 17 maio 2015c.

19. Processo de Qualidade e Acreditação. Disponível em: <http:// www.hemominas.mg.gov.br/intranet/ institucional/diretrizes/acreditacao. html>. Acesso em: 17 maio 2015d.

20. Fundação Hemominas de semente a árvore. Disponível em: $<$ http://www.hemominas.mg.gov.br/ hemominas/menu/aInstituicao/historico. html >. Acesso em: 17 maio 2015e.

21. Doador do Futuro: exercício de cidadania e solidariedade. Disponível em: $<$ http://www. hemominas.mg.gov.br/hemominas/ $\mathrm{menu} / \mathrm{cidadao} /$ doador futuro.html $>$. Acesso em: 17 maio $20 \overline{15 f}$.

22. . Coleta externa. Disponível em: <http://www.hemominas.mg.gov. $\mathrm{br} /$ hemominas/menu/cidadao/coleta 
externa_sangue.html>. Acesso em: 17 maio $2015 \mathrm{~g}$.

23.

Procedimentos de Gestão.

Disponível em: <http:/www.hemominas. mg.gov.br/intranet/qualidade/documentos/ prgs/avalSatClieExtDoadPac/aval satis cliente_ext.pdf $>$. Acesso em: 17 maio 2015.

24. GONTIJO. H. M. D. O. A doação de sangue e o futuro. In: Fundação Hemominas: 1985-2007. Centro de Hematologia e Hemoterapia de Minas Gerais. Belo Horizonte: Fundação Hemominas, p. 191-196, 2007.

25. Doação de Sangue: um compromisso social. In: CIOFFI, Júnia G. M.; RIBEIRO, Denize Q. (Orgs.) Cadernos Hemominas: Capacitação de profissionais de agências transfusionais e assistenciais hemoterápicas. Fundação Centro de Hematologia e Hemoterapia de Minas Gerais. Belo Horizonte: Fundação Hemominas, 2010. 14 v. cap. II, p. 2-4.

26. HARGREAVES, L.; ZUANETTI, R. L. et al. Qualidade em prestação de Serviços. 2. ed. Rio de Janeiro: Senac Nacional, 2001

27. HERRERO FILHO, E. Balanced scorecard e a gestão estratégica: uma abordagem prática. Rio de Janeiro: Campus, 241 p, 2005.

28. KAPlAN, R. S. NORTON, D. P. A estratégia em ação: Balanced Scorecard. 20. ed. Rio de Janeiro: Elsevier, 1997.

29. Colocando em funcionamento o Balanced Scorecard. In: Processo decisório: os melhores artigos de Harvard Business Review. Rio de Janeiro: Elsevier, 2006a. p. 183-212.

30 . Enfrentando problemas com a estratégia? Mapeie-a. In: Processo decisório: os melhores artigos de Harvard Business Review. Rio de Janeiro: Elsevier, 2006b. p. 161-182.

31. KOTLER, P.; LEE, N. R. Social
Marketing: influencing behavior for good. 4. ed. SAGE Publications, 2011.

32. LEFBVRE, R. C. Social marketing and change: strategies and tools for health, well-being, and the environment. New Jersey: John Willey \& Sons, 2013.

33. MALIK, A. M. SCHIESARI, L. M. C. Qualidade na Gestão Local de Serviços e Ações de Saúde. Série saúde e cidadania. v. 3, São Paulo: Faculdade da Universidade de São Paulo, 1998.

34. MATIAS-PEREIRA, J. Curso de Administração Pública: foco nas instituições e ações governamentais. 3. ed. São Paulo: Atlas, 2010.

35. MINAS GERAIS. Secretaria de Estado de Planejamento e Gestão. Plano Plurianual de Ação Governamental 2012-2015: exercício 2014. Belo Horizonte: 2014. 650 p. Disponível em: < http://www.planejamento. mg.gov.br/images/documentos/ ppag/2012-2015/planejamento/ Revis\%C3\%A3o 2014/2014 Vol I PPAG p $\%$ C3\%B3s reforma final. pdf>. Acesso em: 24 mar. 2015.

36. MOWEN, J. C.; MINOR, M. S. Comportamento do Consumidor. São Paulo: Prentice Hall, 2003.

37. ORGANIZAÇÃO NACIONAL DA ACREDITAÇÃO. Coleção Manual Brasileiro de Acreditação: Manual das Organizações Prestadoras de Serviços de Saúde. 6. ed. Brasília: Organização Nacional da Acreditação, 2010.

38. PEREIRA, L. C. B.; SPINK, P. Reforma do estado e Administração Pública Gerencial. 7. ed. Rio de Janeiro: Fundação Getúlio Vargas, 2007.

39. PLANO PLURIANUAL DE AÇÃO GOVERNAMENTAL. Exercício 2013. Disponível em: < http://www.planejamento.mg.gov.br/ images/documentos/ppag/ppag_20152015/revisão 2013/Vol I PPAG Progr e Ações por Rede de Desenvolvimento_Final_2013.pdf $>$. 
Acesso em 21 ago. 2015.

40. RIBEIRO, H. A Bíblia do 5S: da Implantação à Excelência. Salvador: Casa da Qualidade, 2006.

41. SCRIVENS, E. Accreditation: protecting the professional or the consumer? Buckingham, Open University Press, 1995.

42. SILVA, R. C. de V. et al. Relatório do Projeto Doe seu melhor tempo 2011. Relatório. Fundação Centro de Hematologia e Hemoterapia de Minas Gerais. Belo Horizonte: Fundação Hemominas, 2011.

43. . A Comunicação Social na Fundação Hemominas: premissas e resultados. In: SANTOS, Adriana (Org.) Caderno Mídia e Saúde Pública: 20 anos do SUS e60 anos da Declaração dos Direitos Humanos. Escola de Saúde Pública do Estado de Minas Gerais. Belo Horizonte: Escola de Saúde Pública do Estado de Minas Gerais, 2008. p. 109-117.

44. SLOMSKI, V. Controladoria e governança na gestão pública. 1 ed. São Paulo: Ed. Atlas, 2005.

45. VAZ, G. N. Marketing institucional: o mercado ideias e imagens. 2. ed. São Paulo: Pioneira, 2003.

46. WEINREICH, N. K. Hands-on social marketing: a step-by-step guide to designing change for good. 2. ed. California: SAGE Publications, 2011.

Nota: As autoras agradecem o apoio financeiro da Fundação de Amparo à Pesquisa do Estado de Minas Gerais (Fapemig) para a realização deste trabalho. 